\title{
A comparison of different charcoal production technology outputs
}

\author{
Krista Kl̦aviņa*, Dagnija Blumberga \\ Riga Technical University, Faculty of Power and Electrical Engineering, \\ Institute of Energy Systems and Environment, \\ Address: Azenes Street 12/1, Riga, LV-1048, Latvia
}

\begin{abstract}
Charcoal is a renewable material, with a long history of use as the predecessor of fossil fuels, now beginning to regain its place in the market, as the global society is fighting the Climate change. Charcoal along with bio-oils, and pyrolysis gas or syngas is obtained through thermo-chemical conversion of biomass. There are several different turns the charcoal production development has taken. The oldest charcoal production technologies are the batch-type kilns, they are associated with lower costs, and are widely used in the world, mainly in developing countries. A more recent introduction in charcoal production is the continuous operation retort where the biomass is conveyed through different process stages, heating and drying, carbonization, and cooling. This technology draws up high capital investments, but can reach a high level of automation. Apart from these technologies charcoal can be also obtained as a by-product in liquid and gaseous fuel production via pyrolysis and gasification of biomass. Each of the production methods can yield variant quality charcoal with properties distinguishing different charcoal applications. The charcoal use varies from a high capacity fuel to a sustainable soil amendment, adsorbent, source of carbon in chemical reactions, and many more. In this study an evaluation of the charcoal quality parameters, depending on the applied technology, is carried out. The analysed data includes information retrieved from previous studies, as well as an experimental investigation of real life production facility.
\end{abstract}

Keywords: pyrolysis, renewable resources, thermochemical conversion, quality parameters, heating value.

\section{INTRODUCTION}

Seeing the upcoming United Nations Climate Change Conference 2015, held in Paris, France, it is clear that increasingly harsh emission reduction and Climate Change mitigation means are going to be applied. The outcome of this Climate Policy event will cover all countries, and will be implemented starting from 2020. In the European Union are ongoing discussions on setting the emission reduction by $40 \%$ below 1990 level. [1]

A large focus for the emission control has been spared for the alternative energy resources, with a significant part of biomass as an energy resource. As biomass is a renewable material that participates in the active lifecycle of atmosphere carbon, it is assumed to be carbon neutral not like the fossil fuels.

Charcoal in the form of biochar is gaining an increasing attention as an attractive solution for trapping carbon dioxide in the ground. However, the use of charcoal as a substitute for fossil fuels in energy-intensive processes, and renewable biofuel should not be forgotten. A large share of the alternative energy sources can be useful in low temperature systems, as they provide low potential heat, for example waste heat from different industries, ground heat (retriever either by heat pumps or directly), some of the solar technologies etc. Direct biomass fuels on the other hand can provide higher potential energy, though not high enough for the most energy intensive industries. Charcoal is distinct from other wood fuels with its high heating capacity. Good quality charcoal can even exceed the heating capacity of fossil coal. The energy content of good quality charcoal ranges from 28 to $33 \mathrm{MJ} / \mathrm{kg}$. In comparison to the flame temperature of maximum $850{ }^{\circ} \mathrm{C}$ reached by burning wood fuels, the temperature of burning charcoal can reach $2700{ }^{\circ} \mathrm{C}$, withal burning without flame and smoke. [2] This makes it suitable for using in metal smelting and other energy intensive industries, which actually was the initial use of charcoal, and the prerequisite of the development of these industries.

\section{MATERIALS AND METHODS}

The quality of charcoal as a fuel is described by several quality parameters. In this study the selected quality parameters are the moisture content, ash content, and the calorific value of the input and output material. The pyrolysis process is analysed in terms of the changes of these quality parameters due to the thermal conversion. In order to do that a literature study is performed to analyse the batch-type kiln 
productions, but the continuous charcoal production retort has been subjected to a throughout process experimental evaluation. Samples are taken to characterize the feedstock as well as the output production, while registering the retort working temperatures. The samples are tested according to the following methods: Determination of moisture content LVS EN 14774-2:2010 [3], Determination of ash content LVS EN 14775:2010 [4], and Determination of calorific value LVS EN 14918:2010 [5].

The efficiency of conversion of firewood to charcoal is calculated from the overall firewood consumption, and the produced amount of charcoal in the industrial experiment period. The value is calculated for the input firewood at the average moisture content as specified in Table 1.

\section{RESULTS AND DISCUSSION}

\section{A. Batch-type Kilns}

The largest share of the overall charcoal production in the world is produced in different types of batch kilns. The most ancient of which are the pit or mound turf kilns, then slightly upgraded to Casamance kilns by providing exhaust pipes for the pyrolysis gas. These are suitable for small yields, while brick kilns for a larger scale production. In the study by Sparrevik et al. [6] the efficiency of biomass conversion in a brick kiln is stated to be $34.5 \%$. The paper by Bustamante-García et al. [7] states the calorific value in a beahive brick kiln from 25.2 to $33.9 \mathrm{MJ} / \mathrm{kg}$ for branches and cracked firewood. The variation depending on the material, as well as the material position in the kiln. In this study the Moisture content of the produced charcoal varied from 3.2 to $3.9 \%$, and the ash content from 3.7 to $6.7 \%$. In the same type kiln in a paper by Bailis et al. [8] the calorific value of Eucalyptus charcoal is $27.6 \mathrm{MJ} / \mathrm{kg}$.

In a detailed study by Xiong et al. [9] in an experimental batch reactor cotton stalk and bamboo sawdust was pyrolysed. Char with a calorific value of 26 to $28 \mathrm{MJ} / \mathrm{kg}$, and 29 to $32 \mathrm{MJ} / \mathrm{kg}$ respectively was yielded. The char yeald varied from 31.2 to $37.4 \%$ for cotton stalks, and from 31.2 to $37.4 \%$ for bamboo sawdust, while the ash amount in the char varied from 6 to $26 \%$ for cotton stalks, and 4 to $19 \%$ for bamboo sawdust. The variation was dependent on the pysolysis temperature, which was changed from 400 to $800{ }^{\circ} \mathrm{C}$.

In the study by Harouna et al. [10] the pyrolysis of cotton stack in a metal kiln is analysed. The highest heating havlue of the cotton stalk is $19.1 \mathrm{MJ} / \mathrm{kg}$, while for the derived charcoal $22.5 \mathrm{MJ} / \mathrm{kg}$.

The main distinction of more advanced pyrolysis technologies from the traditional kilns is that the process heat is not provided by burning part of the input biomass material, but the process is sustained using the pyrolysis gas produced during the pyrolysis process itself. In this way higher process efficiency is obtained.

The first of the pyrolysis technologies that provided this option are so called Adam retorts. The charcoal yield in an Adam retort stated by Sparrevik et al. [6] is 30.4 to $33.9 \%$.

\section{B. Continuous Retort}

Continuous production retorts are a relatively new technology for charcoal production. There is a gap of knowledge in the field of continuous pyrolysis process, thus an experimental research is commenced in this field. The use of this continuous retorts offer a shorter time span for generation of charcoal, higher process control, and a lower possibility of production loss. One of the main setbacks for the prevalence of this technology is the high capital costs.

The experimental evaluation and the field testing of the industrial Lambiotte SIFIC/CISR 2000 type continuous production retort shows a balanced process and a stable product quality.

The material and product quality is summarized in Table 1.

TABLE 1

CONTINUOUS PRODUCTION MATERIAL QUALITY*

\begin{tabular}{|l|l|l|l|}
\hline Parameter & Units & Input - firewood & Output - charcoal \\
\hline Moisture content & wt-\% & 12.3 & 3.4 \\
\hline Ash content & $\mathrm{wt}-\%$ & 1.0 & 2.8 \\
\hline Gross calorific value of dry mass (at constant pressure) & $\mathrm{MJ} / \mathrm{kg}, \mathrm{d}$ & 18.7 & 32.8 \\
\hline Net calorific value as received (at constant pressure) & $\mathrm{MJ} / \mathrm{kg}$ & 16.1 & 31.2 \\
\hline
\end{tabular}

* Analysis results applies only to the examined samples, since the biomass is an non-homogeneous material

The charcoal quality parameter values in Table 1 are given for an average of five separate loads. The input material is dried in a batch type chamber-dryer, aiming to lower the moisture content of the firewood below 20\%. The output charcoal absorbs moisture from the atmosphere, so the moisture content of the production depends on the storage environment. 


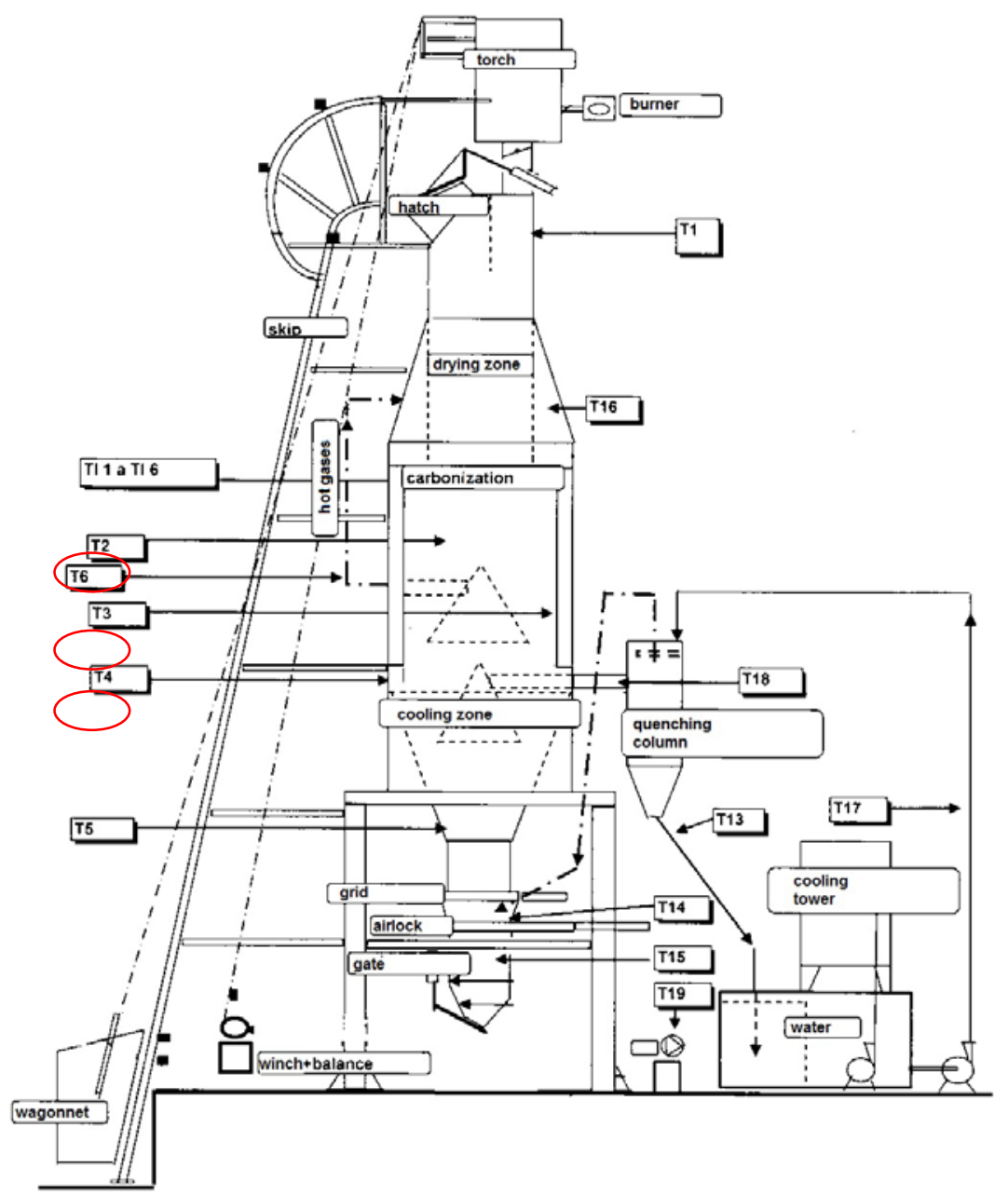

Fig. 1. Schematic representation of the Continuous pyrolysis process retort Lambiotte SIFIC/CISR 2000.

The Fig. 1 shows the schematic of the studied technology. The schematics show the main temperature control parameters (marked with a capital letter T) that are available at the technological process control.

The charcoal is produced in a stabilized mode, with the average carbonization temperature of $560{ }^{\circ} \mathrm{C}$, varying from minimum of $529^{\circ} \mathrm{C}$ to maximum of 591 ${ }^{\circ} \mathrm{C}$ (see Fig. 2).

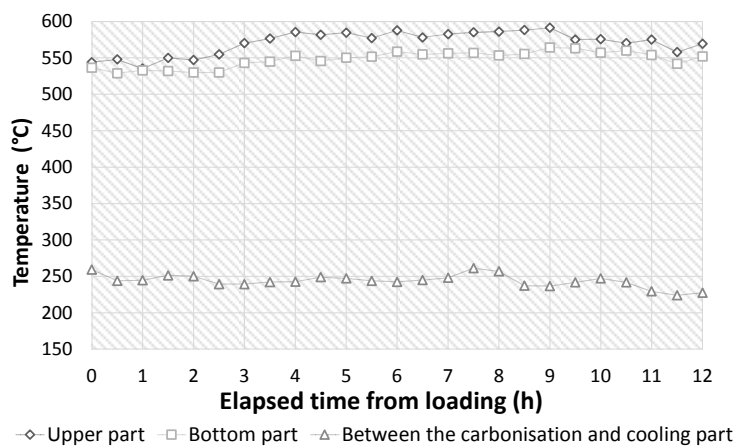

g. 2. Carbonisation process characteristic temperatures in a continuous pyrolysis process retort. In Fig.1 the Upper part temperature measurement point represented as T2, Bottom part as $\mathrm{T} 3$, and between the carbonisation and cooling part as T4
The conversion efficiency in terms of produced charcoal mass is discovered to be $62 \%$. In other words one $\mathrm{kg}$ of charcoal is obtained from $1.6 \mathrm{~kg}$ of firewood (at $12.3 \%$ moisture content).

\section{Charcoal as a By-product}

If the pyrolysis process is aimed at a higher share of bio-oil or pyrolysis gas production, the produced charcoal amount and quality will be lowered. The pyrolysis of beech wood in a steel reactor was undergone in the study by Demirbas [11]. This study points out that while the bio-oils are produced the obtained char has a satisfying quality to be used as a biofuel. The obtained char has the highest heating value of $33.2 \mathrm{MJ} / \mathrm{kg}$.

\section{Hydrothermal Carbonization}

Hydrothermal carbonization is a thermo-chemical process undergone in the presence of water at increased temperatures and pressure. The process produces a material in the form of a char-water-slurry, the char can be separated and dried. This method is suitable for biomass feedstock with a very high moisture content, such as sewage sludge. The energy 
content of the obtained chars at carbonization temperatures from 140 to $200{ }^{\circ} \mathrm{C}$ range from 21.5 to $23.3 \mathrm{MJ} / \mathrm{kg}$, using sewage sludge as a feedstock. [12]

In the study by Álvarez-Murillo et al. [13] olive stones were used as the input biomass. The Hydrothermal carbonisation yealded a fuel with the highest heating value from 22.2 to $29.6 \mathrm{MJ} / \mathrm{kg}$. This is a similar result as in the study mentioned previously. The main advantage for this method is the energy densification that otherwise would be spread in the body of the wet sludge, giving an oppurtunity to recover valuable energy.

In the study by Lench Nowicki and Maciej Markowski [14] pyrolysis of dried sewage sludge in a fixed-bed reactor is performed, and the obtained char has a heating value of 5.6 and $9.8 \mathrm{MJ} / \mathrm{kg}$, with an ash content of 85.6 and 69.1 wt.\%. The pyrolysis was performed at $1000{ }^{\circ} \mathrm{C}$. Although the initial material characteristics used in the hydrothermal carbonisation experiments are not given, it could be inclined that for biomass with a very high moisture content as sewage sludge, hydrothermal carbonisation returns char with the calorific value suitable for using it as a fuel.

\section{CONCLUSIONS}

The produced charcoal quality is directly related to the material that is used as the feedstock. Nonetheless the selected pyrolysis technology also significantly influences the received product. In batch-type kilns a non-homogenous product quality can be suspected. The advantage of a continuous type pyrolysis retort from the experimental evaluation stands out the high mass convertion share of around $60 \%$ while that of above $30 \%$ for the traditional batch-type technologies. There is a lack of data to make concluding statements for the comparison of the obtained charcoal quality, as the used material has such a high influence. The experimental evaluation of the industrial production in a continuous retort reveals satisfying results in terms of the obtained charcoal quality. The densified energy in the charcoal makes it suitable for using as a substitute or an addition in a fuel mix for energy intensive manufacturing, such as metal smelting. However the increased ash content has to be reckoned when working with charcoal.

\section{$\mathrm{V}$ ACKNOWLEDGEMENTS}

The work has been supported by the National Research Program "Energy efficient and low-carbon solutions for a secure, sustainable and climate variability reducing energy supply (LATENERGI)”.

\section{REFERENCES}

[1] European Commission, "Climate Action: The 2015 international agreement," 2015. [Online]. Available: http://ec.europa.eu/clima/policies/international/negotiations/fu ture/index_en.htm. [Accessed: Mar 06, 2015].

[2] M. Guo, W. Song. J. Buhain, "Bioenergy and biofuels: History, status, and perspective," Renewable and Sustainable Energy Reviews, vol. 42, pp. 712-725, 2015.

[3] Latvijas standarts, "Solid biofuels - Determination of moisture content - Oven dry method - Part 2: Total moisture Simplified method," 2010.

[4] Latvijas standarts, "Solid biofuels - Determination of ash content," 2010.

[5] Latvijas standarts, "Solid biofuels - Determination of calorific value," 2010.

[6] M. Sparrevik, C. Adam, V. Martinsen, Jubaedah, G. Cornelissen, "Emissions of gases and particles from charcoal/biochar production in tutal areas using medium-sized traditional and improved "retort" kilns," Biomass \& Bioenergy, vol. 72, pp. 65-73, 2015.

[7] V. Bustamante-García, A. Carrillo-Parra, H. GonzálezRodríguez, R.G. Ramírez-Lozano, J.J. Corral-Rivas, F. GarzaOca nas, "Evaluation of a charcoal production process from forest residues of Quercus sideroxyla Humb., \& Bonpl. in a Brazilian beehive kiln," Industrial Crops and Products, vol. 42, pp. 169-174, 2013.

[8] R. Bailis, C. Rujanavech, P. Dwivedi, A. de Oliveira Vilela, H. Chang, R.C. de Miranda, "Innovation in charcoal production: A comparative life-cycle assessment of two kiln technologies in Brazil," Energy for Sustainable Development, vol. 17, pp. 189-200, 2013.

[9] S. Xiong, S. Zhang, Q. Wu, X. Guo, A. Dong, C. Chen, "Investigation on cotton stalk and bamboo sawdust carbonization for barbecue charcoal preparation," Bioresource Technology, vol. 152, pp. 86-92, 2014.

[10] I.G. Harouna, O. Sanogo, T. Daho, S.K. Ouiminga, A. DanMaza, "Determination of processes suitable for cotton stalk carbonization and torrefaction by partial combustion using a metal kiln," Energy for Sustainable Development, vol. 24, pp. 50-57, 2015

[11] A. Demirbas, "Determination of calorific values of bio-chars and pyro-oils from pyrolysis of beech trunkbarks," Journal of Analytical and Applied Pyrolysis, vol. 72, pp. 215-219, 2004.

[12] P. Zhao, Y. Shen, S. Ge, K. Yoshikawa, "Energy recycling from sewage sludge by producing solid biofuel with hydrothermal carbonization," Energy Conversion and Management, vol. 78, pp. 815-821, 2014.

[13] A. Álvarez-Murillo, S. Román, B. Ledesma, E. Sabio, "Study of variables in energy densification of olive stone by hydrothermal carbonization," Journal of Analytical and Applied Pyrolysis, p. Article in Press, 2015.

[14] L. Nowicki, M. Markowski, "Gasification of pyrolysis chars from sewage sludge," Fuel, vol. 143, pp. 476-483, 2015. 